\title{
Determinants of Income Differences of Farmers in Turkey: A Discriminate Analytical Approach
}

\author{
*Filiz KADI, Zehra Vildan SERIN, Fatma Eban ARIKAN \\ Fatih University, Istanbul, Turkey \\ *fkadi@fatih.edu.tr
}

\begin{abstract}
This study aims to investigate the key factors of income of farmers for Turkey. Primary data is collected from the interviews of 300 farmers from five different regions of Turkey in 2014. Empirical study reveals positive effects of state size, estate ownership, education levels of farmers, and number of tractor on farmers' income. This paper specifically focuses on the contribution of land distribution policies of Turkey to enhance farmers' income.
\end{abstract}

Keywords: Farmers' income, productivity, Turkish farmers

\section{Introduction}

Food security and sustainably increasing agriculture productivity is one of the fundamental goals of the world. There are 1.4 billion people living in extreme poverty, including 925 million who suffer from hunger and more than 200 million children under five who suffer from malnutrition (United Nations Agriculture Development and Food Security, 2012). In order to overcome hunger and poverty, agricultural productivity should be strengthened throughout the world, mostly in developing countries. According to the United Nations' estimation, agricultural productivity should be increased \% 60 in all over the world, in order to reduce by half the proportion of people who suffer from hunger by 2015. The purpose of this paper is to determine the factors influencing farmer's income in Turkey. Using discriminate analysis, five different variables are selected in this study, namely, education levels of farmers, land size of farmers is used, land type of farmers (owner, rent, shareness, contracted), number of tractor, participating agricultural training programs. Farmers' income levels are classified as low, medium and highlevel based on actual survey is conducted from January to July, 2014 in five different regions of Turkey.

\section{Literature Review}

Several studies examine the challenges of achieving agricultural productivity provide an update on progress in implementing sustainable agricultural policies, especially, in developing countries. Economic literature suggests that productivity growth is the main force behind farmer's income and welfare. Goletti et al. (2001) analyzed changes in farmer income over the period 1997-2001 for Nepal. This study indicated an improvement in farmer income and livelihood and also a reduction of poverty. Substantial studies investigated the effect of land size and land management on farmers' income levels in different regions of the world. Specifically, a previous survey which is conducted in five countries Ethiopia, Kenya, Mozambique, Rwanda, and Zambia, from 1990 to 2000 suggested that rate of growth is likely to be affected by the distribution of land (Jayne et al., 2005). The growing concern about land resource management has increased to the attention of land consolidation in many countries. Huang et al. (2006) analyzed the effects of land consolidation in Beitun Oasis, China. Similarly, Crecente et al. (2002) showed that land consolidation is the main planning instrument to increase the welfare of rural areas in Galicia.

Meuser's comparative study that is based on 11 Central and Western European countries pointed out the strong relationships between land consolidation and rural development 
policies. Lio and $\mathrm{Hu}$ also found that land size has a significant positive impact on the income of the farmers (Lio and $\mathrm{Hu}, 2009$ ). Using the stochastic frontier production function, Ahmad estimated the input elasticity of production of poor and rich farms. This study emphasized that the land distribution and land reforms are favor of small farmers (Ahmad, 2003). Another study implied that government interventions to land lease markets provides little benefit for agricultural efficiency in Ethiopia (Pender \& Marcel, 2001). Jianglong and Wen analyzed that the relations between the allocation in space of land resource and the sustainable use of land in China (Jianglong et al., 2004). Adamopoulos (2011) investigated the impact of transportation costs on agricultural productivity. Ravallion and Datt (2002) found that greater equity in land holding reduces rural poverty in the short run.

Also, Gollin, Parente and Rogerson (2002) showed that improvements in agricultural productivity effects on a country's relative income examining data for the 1960-1990 period for a set of 62 countries defined as developing by the Food and Agriculture Organization of the United Nations. They found that there was a positive relationship between the growth in a country's agricultural productivity and the movement of labor out of agriculture. They also concluded that productivity growth, along with the ensuing sectoral shifts in employment, was an important source of economic growth for these countries. Hicks (1987) indicated that human capital is a major factor explaining the differences in productivity and income between countries (Hicks, 1987). Kendrick and Grossman found not only formal education but also on the job or specific training is an important source of productivity growth (Kendrick and Grossman, 1981).

The effect of formal and informal education on farmer's income levels, also, has long been analyzed in economics literature. Serin, Bayyurt, Civan (2007) indicated that the effects of informal education on Turkish farmers very significant. Serin and Arıcan (2006) found that land fragmentation was obstacle for Turkish farmers in order to improve their incomes. Specifically Anderson (1997) suggested that education and training are essential for managing and promoting the changes that farmers are to be sustainable. Kilpatrick (1997) showed that farm businesses with managers who had participated in more education and training is more profitable. Lockheed, Jamison and Lau (1980) indicated that a positive effect of education upon output. They noted that a significant positive relationship was more likely to be found in areas where farmers are modernizing. Phillips (1994) found that the average increase in output owing to an additional four years of schooling. Mirotchie (1994) investigated technical efficiency in cereal crop production in Ethiopia using aggregate data for the period 1980-86. He reported that primary schooling tends to increase productivity, while secondary schooling has no effect. Serin et al. (2009) surveyed from 23 cities and 7 geographic regions in Turkey in order to analyze the effects of education and training on farmer's income. They found that positive effects of formal education on farmers' income levels. Ashenfelter and Kruger (1994) showed that omission of skill level did not cause upward bias in returns to education in the U.S. However; authors like Lees and Reeve (1991) and Moore (1990) are skeptical about the role of education on farming businesses. They argued that human beings are endowed with farming skills by nature; hard working and local knowledge are sufficient to be effective farmers. Similarly Appleton and Balihuta (1996) pointed out that education was not found to be significant. Yang (2006) indicated that Chinese farmers witnessed the highest annual income increase in 2005 due to training of young farmers. This paper that is developed in the previous literature, examines the determinants that influence the annual income of farmers in the five regions of Turkey.

\section{Methodology}

Discriminant analysis is one of the multivariable analysis techniques that compare at least two groups according to variables which are obtained. Discriminant Function Analysis (DA) undertakes the same task as multiple linear regressions by predicting an outcome. DA involves 
the determination of a linear equation like regression that will predict which group the case belongs to. The form of the equation or function is:

$D=\beta_{0}+\beta_{1} X_{1}+\beta_{2} X_{2}+\cdots+\beta_{n} X_{n}$,

Where $\mathrm{D}=$ discriminate function

$\beta_{n}=$ the discriminant coefficient or weight for that variable

$X_{n}=$ respondent's score for that variable

$\beta_{0}=\mathrm{a}$ constant

$\mathrm{n}=$ the number of predictor variables

One of the mains the features of the function is that variance of between groups are greater than the variance of within groups. This condition is explained by Fischer as following:

$$
f\left(\beta_{1}, \beta_{2}, \ldots, \beta_{n}\right)=\frac{A^{\prime} B A}{A^{\prime} W A}
$$

A: $\mathrm{n} \times 1$ coefficient vector; $\mathrm{B}: \mathrm{n} \times \mathrm{n}$ variance matrices between groups, $\mathrm{W}: \mathrm{n} \times \mathrm{n}$ variance mat rice within groups. $\mathrm{A}^{\prime}$ is transpose of mat rice A. The aim of the statistical analysis in DA is to combine (weight) the variable scores in some way so that a single new composite variable, the discriminant score, is produced. To investigate differences between groups on the basis of the attributes of the cases, indicating which attributes contribute most to group discrimination. The descriptive technique successively identifies the linear combination of attributes known as canonical discriminant functions (equations) which contribute maximally to group separation. The $\beta$ 's are unstandardized discriminant coefficients analogous to the b's in the regression equation. These $\beta$ 's maximize the distance between the means of the criterion (dependent) variable. Standardized discriminant coefficients can also be used like beta weight in regression. The number of discriminant functions is one less the number of groups. There is only one function for the basic two group discriminant analysis. If the groups are more than two, then values are used instead of in the function (2).

The coincidence between the projections on the line B of points in the two dimensional space will be less. So, the function converts two separate values of a variable for an individual to a unique value of discriminant function. In this case, if there are two groups then just one separator function is enough, but if there are more than two groups then one discriminant function will not be enough. The number of discriminant function must be one less than the number of groups. Besides, the first discriminant function will be the connection that satisfies the biggest distinction between the groups. Other functions discriminate on regions where the first one cannot reach.

$\lambda_{i}=\frac{A^{\prime} B A}{A^{\prime} W A}$

The eigenvectors generated by the eigenvalues $\lambda_{i}$ will the functions that satisfy the stated conditions. Taking derivative of the given equation (3) with respect to $\mathrm{A}$ and rearranging, $W^{-1} \mathrm{~B}$ $-\lambda \mathrm{I}=0$ is obtained. Therefore, the eigenvalues $\lambda_{i}$ can be found by solving the determinant $W^{-1} \mathrm{~B}$ $-\lambda \mathrm{I}=0$ and it can writen that $\mathrm{m}=\mathrm{min}(\mathrm{k}-1, \mathrm{n})$. M eigenvectors corresponding to the eigenvalues $\lambda_{1} \lambda_{2}, \ldots, \lambda_{m}$ will be the investigated seperator functions. In addition, since it is important, especially in interpreting, that the distinction effects of the variables of functions or knowing the level of contributions to function, it is better to standardize the formula as the following;

$\beta_{i}^{*(j)}=\left(\beta_{i}^{(j)} W_{i i}\right)^{1 / 2} \quad \mathrm{i}=1,2, \mathrm{n}$ ve $\mathrm{j}=1,2, \mathrm{~m}$

The efficiency of discriminant function that has more than two groups is tested variance criteria Lambda which is improved by Wilks.

$\Lambda=\frac{|W|}{|T|}=\frac{|W|}{|W+B|}$

$\mathrm{W}$ and $\mathrm{T}$ are in-group and total-variance matrices, respectively. To find a low value for the proposed $\Lambda$ is an important sign for the distincness of the groups. If the numbers of individuals 
in the groups are large enough, then by taking $\mathrm{p}=\mathrm{N}-1-(\mathrm{n}+\mathrm{m}) / 2$, the value of the test statistics will be as the following;

$\chi^{2}=-m \log (\Lambda) \sim \chi_{n(m-1) ; \alpha}^{2}$

Here, the statistics of the test has $\chi^{2}$ distribution with degree of freedom $n(m-1)$

If the function used in classification of individuals is investigated, it can be seen that for individuals $\mathrm{n}$ variables are regarded and according to these variables the separate functions based on the distance of each other are obtained. The distance between any individual and the average vector of a group can also be found in the classifications.

$d_{i j}^{2}=\left(x_{i}-\bar{x}^{(j)}\right)^{\prime} C^{-1}\left(x_{i}-\bar{x}^{(j)}\right) i=1, \ldots, n ; j=1, \ldots, k$

$d_{i j}^{2}$ : Distance, It is decided that in which class will be the individuals where $d_{i j}^{2}$ represents distance and $\mathrm{C}$ represents estimation for variance-covariance matrix of the population. One of the important indicators for the validity of the results of Discriminant analysis is high percentage of the correct classification.

\section{Results}

Main data of this research is provided primary data by implementing the survey method that is interviewed 300 farmers from selected five regions of Turkey in 2014. A personal interview survey, also called as a face-to-face survey, is implemented to explore the responses of the people to gather more and deeper information. Also, this survey method is presented a greater opportunity to observe the attitude and behavior of farmers/consumers toward a product. We achieved to interview with 300 farmers, however 190 suitable survey dates are used for this analysis. It is benefited from SSPS19 packet program and farmers' income levels are classified as low, medium and high-level based on actual survey is conducted from January to July, 2014 in five different regions of Turkey.

Table1: Distribution of participants by region

\begin{tabular}{llllll}
\hline & & Frequency & Percent & $\begin{array}{l}\text { Valid } \\
\text { Percent }\end{array}$ & Cumulative Percent \\
\hline Valid & Mediterranean & 27 & 14,2 & 14,2 & 14,2 \\
& Southeast & 75 & 39,5 & 39,5 & 53,7 \\
& Black sea & 56 & 29,5 & 29,5 & 83,2 \\
& Marmara and Aegean & 32 & 16,8 & 16,8 & 100,0 \\
& Total & 190 & 100,0 & 100,0 & \\
\hline
\end{tabular}

Table 2: Distribution of participants by age

\begin{tabular}{|c|c|c|c|c|c|}
\hline & & Frequency & Percent & Valid Percent & $\begin{array}{l}\text { Cumulative } \\
\text { Percent }\end{array}$ \\
\hline \multirow[t]{6}{*}{$\overline{\text { Valid }}$} & $15-18$ & 3 & 1,6 & 1,6 & 1,6 \\
\hline & $18-25$ & 8 & 4,2 & 4,2 & 5,8 \\
\hline & $25-35$ & 32 & 16,8 & 16,8 & 22,6 \\
\hline & $45-60$ & 43 & 22,6 & 22,6 & 45,3 \\
\hline & $60+$ & 105 & 55,3 & 55,3 & 100,0 \\
\hline & Total & 190 & 100,0 & 100,0 & \\
\hline
\end{tabular}

This research is designed to address two objectives. First goal is to identify and rank the factors which are influenced on the income of farmers in Turkey. Second purpose is to contribute the land management and distribution policy of Turkey. Using discriminate analysis, five different variables are selected in this study, namely, education levels of farmers, land size of farmers is used, land type of farmers (owner, rent, shareness, contracted), number of tractor, participating agricultural training programs. Farmers' income levels are classified as low, medium and highlevel based on actual survey is conducted from January to July, 2014 in five different regions of Turkey. 
Table 3: Social security of participants

\begin{tabular}{|c|c|c|c|c|c|}
\hline & & Frequency & Percent & Valid Percent & $\begin{array}{l}\text { Cumulative } \\
\text { Percent }\end{array}$ \\
\hline \multirow[t]{8}{*}{$\overline{\text { Valid }}$} & Non & 22 & 11,6 & 11,6 & 11,6 \\
\hline & Green card & 9 & 4,7 & 4,7 & 16,3 \\
\hline & $\mathrm{SSK}^{*}$ & 45 & 23,7 & 23,7 & 40,0 \\
\hline & Self-employed & 48 & 25,3 & 25,3 & 65,3 \\
\hline & SSK from couple & 40 & 21,1 & 21,1 & 86,3 \\
\hline & SSK from parents & 17 & 8,9 & 8,9 & 95,3 \\
\hline & Other & 9 & 4,7 & 4,7 & 100,0 \\
\hline & Total & 190 & 100,0 & 100,0 & \\
\hline
\end{tabular}

* Social Insurance Institution: Workers employed under a service contract

Table 4: Memberships of an Institution

\begin{tabular}{llllll}
\hline & & Frequency & Percent & Valid Percent & $\begin{array}{l}\text { Cumulative } \\
\text { Percent }\end{array}$ \\
\hline Valid & Non member & 91 & 47,9 & 47,9 & 47,9 \\
& Cooperative & 26 & 13,7 & 13,7 & 61,6 \\
& Agr. associations & 6 & 3,2 & 3,2 & 64,7 \\
& Chamber of agr. & 50 & 26,3 & 26,3 & 91,1 \\
& Others & 17 & 9 & 9 & 100 \\
& Total & 190 & 100,0 & 100,0 & \\
\hline
\end{tabular}

Table 5 shows group statistic of farmers who are the subject of research. There are three different groups according to agricultural income level. First group reveals low income level of farmer who earns 10.000 TL or less yearly. Second group indicates middle income level of farmer who earn between 10.001- 35.000 yearly. The last group shows high income level of farmer who make Money more than 35.001 TL yearly. Results can be read that agricultural income levels of farmers decompose according to land size, numbers of tractor.

Table 5: Group Statistics

\begin{tabular}{llllll}
\hline \multirow{2}{\text{Income}}{} & & Mean & Std. Deviation & Unweighted & Weighted \\
\hline Low & Education & 3,01 &, 767 & 91 & 91,000 \\
& Land type & 1,99 &, 483 & 91 & 91,000 \\
& Land size & 2,51 & 1,168 & 91 & 91,000 \\
& Tractor & 1,41 &, 699 & 91 & 91,000 \\
& Training & 1,77 &, 424 & 91 & 91,000 \\
Medium & Education & 3,06 &, 791 & 47 & 47,000 \\
& Land type & 2,06 &, 247 & 47 & 47,000 \\
& Land size & 3,83 & 1,633 & 47 & 47,000 \\
& Tractor & 1,53 &, 687 & 47 & 47,000 \\
& Training & 1,79 &, 414 & 47 & 47,000 \\
High & Education & 2,94 &, 791 & 36 & 36,000 \\
& Land type & 2,00 &, 239 & 36 & 36,000 \\
& Land size & 4,44 & 1,664 & 36 & 36,000 \\
& Tractor & 2,11 & 1,369 & 36 & 36,000 \\
& Training & 1,42 &, 500 & 36 & 36,000 \\
& Education & 3,01 &, 775 & 174 & 174,000 \\
& Land type & 2,01 &, 387 & 174 & 174,000 \\
& Land size & 3,26 & 1,630 & 174 & 174,000 \\
& Tractor & 1,59 &, 913 & 174 & 174,000 \\
& Training & 1,70 &, 459 & 174 & 174,000 \\
\hline
\end{tabular}


Table 6: Correlation Coefficient

\begin{tabular}{lllllll}
\hline & & Education & Land size & Land type & Tractor & Training \\
\hline Correlation & Education & 1,000 & & & & \\
& Land size &,- 003 & 1,000 & & & \\
& Land type &,- 208 &,- 074 & 1,000 & & \\
& Tractor &,- 110 &, 100 &, 310 & 1,000 & \\
& Training &,- 057 &, 048 &, 135 &,- 089 & 1,000 \\
\hline
\end{tabular}

Table 6 includes the mutual correlation coefficient reflects the relationships between the independent variables. Low mutual correlation coefficient indicates that each argument provides its own contribution to the model. Accordingly, it can be said that the data used in the study cannot replace each other.

Table 7: Tests of Equality of Group Means

\begin{tabular}{llllll}
\hline & Wilks' Lambda & F & df1 & df2 & Sig. \\
\hline Education &, 997 &, 240 & 2 & 171 &, 787 \\
Land type &, 993 &, 595 & 2 & 171 &, 553 \\
Land size &, 744 & 29,368 & 2 & 171 &, 000 \\
Tractor &, 910 & 8,466 & 2 & 171 &, 000 \\
Training &, 899 & 9,609 & 2 & 171 &, 000 \\
\hline
\end{tabular}

In Table 7 Wilks' Lambda values have been showed that variables can be collected in different discriminate groups and these discriminate groups are significant. High $\mathrm{F}$ value and significant level $(\mathrm{p}<0.05)$ reveal that land size, tractor numbers and participating training are important separators in terms of agricultural income level.

Table 8: Eigenvalues

\begin{tabular}{lllll}
\hline Function & Eigenvalue & \% of Variance & Cumulative \% & $\begin{array}{l}\text { Canonical } \\
\text { Correlation }\end{array}$ \\
\hline 1 &, $479^{\mathrm{a}}$ & 86,4 & 86,4 &, 569 \\
2 &, $075^{\mathrm{a}}$ & 13,6 & 100,0 &, 265 \\
\hline
\end{tabular}

Two discriminant functions have been established for three different levels of agricultural income. The first discriminant function meets $86.4 \%$ of the variance of change; the second function meets the rest (13.6\%). The first function of the model is successful by $59 \%$ in the content of discrimination. All ratios above $40 \%$ is considered to be statistically important. e 8 . Annual income functions are three in this research that is why the most two function are reached as shown in Table 8.

Table 9: Wilks' Lambda

\begin{tabular}{lllll}
\hline Test of Function(s) & Wilks' Lambda & Chi-square & df & Sig. \\
\hline 1 through 2 &, 629 & 78,405 & 10 &, 000 \\
2 &, 930 & 12,261 & 4 &, 016 \\
\hline
\end{tabular}

Wilks' lambda indicates the significance of the discriminant function. Table 9 shows Wilks' Lambda values and the significance of the function of annual agricultural income is generated. The first function is significant with $(p=0.000)$, Wilks' Lambda degrees of freedom value is 10 and Chi-square 78,405. Second function is also significant with $p=0.016$ value however other parameters are weaker than the first function. Moreover the first function results are overlap finding of the upper data. In this case only the first function will be appropriate the discrimination of annual agricultural income level. 
Table 10: Canonical Discriminant Function Coefficients

\begin{tabular}{ll}
\hline Education &, 180 \\
Land type &, 330 \\
Land size &, 643 \\
Tractor &, 112 \\
Training & $-1,154$ \\
(Constant) & $-1,520$ \\
\hline
\end{tabular}

The interpretation of the discriminant coefficients (or weights) is like that in multiple regressions. Table 10 provides an index of the importance of each predictor like the standardized regression coefficients (beta's) did in multiple regression. The sign indicates the direction of the relationship. These unstandardized coefficients (b) are used to create the discriminant function (equation)

The discriminant function is;

$\mathrm{D}=-1.154$ training $+0,643$ land size $+0,330$ land type $+0,112$ tractor $+0,180$ education -1.520

Table 11: Structure Matrix

\begin{tabular}{ll}
\hline Land size &, $834^{*}$ \\
Tractor &, $423^{*}$ \\
Training &,- 393 \\
Land type &, 046 \\
Education &,- 031 \\
\hline
\end{tabular}

Table 11 provides another way of indicating the relative importance of the predictors and it can be seen above that the same pattern holds. Many researchers use the structure matrix correlations because they are considered more accurate than the Standardized Canonical Discriminant Function Coefficients. The structure matrix table (Table 11) shows the correlations of each variable with each discriminate function. These Pearson coefficients are structure coefficients or discriminant loadings. They serve like factor loadings in factor analysis. According to structure matrix "land size" is positive and the highest predictive. Land size is the most significant factor in differentiating factor of the annual income. The second significant factor is number of tractors while training takes the third place. Land type and education level have low scores.

Table 12: Classification Results ${ }^{\mathrm{a}}$

\begin{tabular}{clllll}
\hline & & \multicolumn{4}{l}{ Predicted Group Membership } \\
\cline { 4 - 6 } Count & Income & 1,00 & 2,00 & 3,00 & Total \\
& 1,00 & 88 & 8 & 6 & 102 \\
& 2,00 & 28 & 21 & 3 & 52 \\
\multirow{2}{*}{$\%$} & 3,00 & 12 & 10 & 14 & 36 \\
& 1,00 & 86,3 & 7,8 & 5,9 & 100,0 \\
& 2,00 & 53,8 & 40,4 & 5,8 & 100,0 \\
& 3,00 & 33,3 & 27,8 & 38,9 & 100,0 \\
\hline
\end{tabular}

$64.7 \%$ of original grouped cases correctly classified.

By using the discriminant function the correct classification of the annual agricultural income of farmers are given in Table 12 . Correct classification rate are respectively $86.3 \%, 40.4 \%$ and \%38.9. In total correct classification rate is $64.7 \%$ in three different categories and this rate is higher the classification performance than expected. In this case, the results of analysis in research have been demonstrated that five factors are significant in the agricultural income levels of farmers that are subject to discrimination. 


\section{Conclusion}

Agriculture is practically the only income source for the rural population in Turkey. Our results suggests that land size substantially effects the farmers' income and the fragmentation of agricultural lands, reduces agricultural income. This finding shows policy makers the importance of land consolidation in order to increase farmers' income and agricultural productivity in Turkey. Despite Turkey attempted to consolidate fragmented agricultural fields in 1961, only 4 percent of fragmented land was consolidated by 2003. Land fragmentations cause migration from rural area to urban centers in Turkey, due to rural residents live in much inferior conditions than urban residents. It is necessary to improve of farmer income level is to reduce the gap between living conditions levels of rural and urban residents. Policy makers should use land consolidation as a tool for improving the farmer's income in Turkey. Moreover; besides obvious factors like estate size or; land types and number of tractors are found to be influencing farmer income levels. Government also should implement policies to increase both the utilization rate and availability of technical expertise at rural areas.

\section{References}

Ashenfelter, O. \& Krueger, A. B. (1994). Estimating the returns to schooling using a new sample of twins. Am. Econ. Rev., 84(5), 1157-1173.

Appleton, S. \& Balihuta, A. (1996). Education and agricultural productivity: evidence from Uganda. Journal of International Development, 8(3), 415-444.

Adamopoulos, T. (2011). Transportation Costs, Agricultural Productivity, and Cross-Country Income Differences. International Economic Review, 52(2), 489-521.

Ahmad, M. (2003). Agricultural Productivity, Efficiency, and Rural Poverty in Irrigated Pakistan: A Stochastic Production Frontier Analysis. The Pakistan Development Review, 42(3), 219-248.

Anderson, J. (1997). Agriculture - advancing Australia, A statement by the Primary Industries and Energy Minister. Canberra, Commonwealth of Australia.

Business Council for Effective Literacy (1993). The Connection between Employee Basic Skills \& Productivity. BCEL-Brief number 8. New York, Workforce \& Workplace Literacy Series.

Crecentea, R., Alvareza, C. \& Frab, U. (2002). Economic, Social and Environmental Impact of Land Consolidation in Galicia. Land Use Policy, 19(2), 135-147.

Goletti F., Bhatta, A. \& Gruhn, P. (2001). Crop Production and Productivity Growth in Nepal. Discussion Paper No. 2, Agricultural Sector Performance Review, TA 3536-NEP, Kathmandu, Nepal, pp. 83.

Gollin, L., Parente, K. \& Rogerson, L. (2002). The Role of Agriculture in Development, Department of Economics Working Papers 2002-09.

Hicks, N. (1987). Education and Economic Growth. In G. Psacharopoulos (Ed), Economics of Education: Research and Studies. Oxford, Pergamon Press, 101-107.

Huang, J., Wang, R. \& Zhang, Z. (2006). Land Consolidation and GIS Application in Xinjiang, China, Proc. SPIE 6411, Agriculture and Hydrology Applications of Remote Sensing, 64111S (December 12, 2006); http://dx.doi.org/10.1117/12.693805

Jayne, T. S., Mather, D. \& Mghenyi, E. (2005). Smallholder Farming in Difficult Circumstances: Policy Issues for Africa, The Future of Small Farms, 103.

Jianglong, C., Futian, Q. \& Wen, C. (2004). The Dissimilarity in Space of the Non-agricultural Efficiency of Farmland, and its Inspiration to the Policy Adjustment of Use of Land [J]. Management World.

Kendrick, J. \& Grossman, E. (1981). Productivity in the United States: Trends and Cycles. Southern Economic Journal, 47(4).

Kilpatrick, S. (1997). Education and Training: Impacts on Profitability in Agriculture. Australian and New Zealand Journal of Vocational Education Research, 5(2), 11-36.

Lees, J. W. \& Reeve, I. J. (1991). Competencies for Farming: a Compendium of Profiles. Armidale, New South Wales, the Rural Development Centre, University of New England. 
Lio, M. \& Hu, M. J. (2009). Governance and Agricultural Production Efficiency: A Cross-Country Aggregate Frontier Analysis. Journal of Agricultural Economics, 60(1), 40-61.

Lockheed, M., Jamison, D. \& Lau, L. (1980). Farmer Education and Farm Efficiency: A Survey. In King, T. (Ed.) Education and Income. World Bank Staff Working Paper No.402, World Bank: Washington.

Mirotchie, M. (1994). Technical efficiency of Ethiopian agriculture, in Berhanu Abegaz, ed., Essays on Ethiopian Economic Development.

Moore, K. (1990). Learning on the Farm. The Educational Background and Needs of New Zealand Farmers. Wellington, New Zealand Council for Educational Research.

Pender, J. \& Marcel, F. (2001) Land Lease Markets And Agricultural Efficiency: Theory And Evidence From Ethiopia. Environment and Production Technology Division, International Food Policy Research Institute. http://www.ifpri.org/sites/default/files/publications/eptdp81.pdf

Phillips, J. M. (1994). Farmer education and farmer efficiency: a meta-analysis. Economic Development and Cultural Change, 43, 149-165.

Ravallion, M. \& Datt, G. (2002). Why Has Economic Growth Been More Pro-poor In Some States of India Than Others? Journal of Development Economics, 68, 381-400.

Serin, V. \& Arıcan, E. (2006). Dünya Ticaret Örgütü ve AB İkileminde Türkiye' nin Tarım Politikaları. TASAM Stratejik Öngörü Dergisi, 3(8), 68-78.

Serin, V., Bayyurt, N. \& Civan, K. (2007). The Impacts of Education on Farmer's Productivity: A Survey analysis. Ruralearn Lifelong Learning For Rural Europe, Chios, Greece. Rural Learning for Development Experiences from Europe Report on, 1, 166-177.

Serin, V., Bayyurt, N. \& Civan, K. (2009). Effects of Formal Education and Training on Farmers income. European Journal of Social Sciences, 7(3), 52-62.

United Nations Agriculture Development and Food Security. (2012). http://www.un.org/esa/dsd/susdevtopics/sdt_pdfs/SG\%20Report\%20on\%20Agricul ture\%20Development\%20and\%20Food\%20Security.pdf

Yang, D. L. (2006). Economic Transformation and its Political Discontents in China: Authoritarianism, Unequal Growth, and the Dilemmas of Political Development. Annu. Rev. Polit. Sci. 9,143-164. http://www.annualreviews.org /doi/abs/10.1146/annurev.polisci.9.062404.170624 